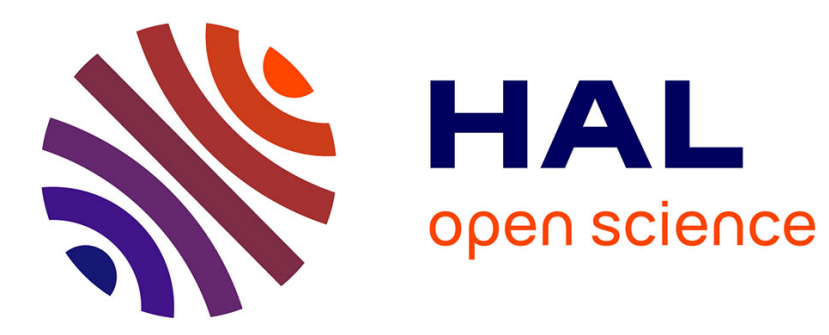

\title{
Does sex influence the network structure of psychopathy?
}

Jonathan Bronchain, Patrick Raynal, Henri Chabrol

\section{To cite this version:}

Jonathan Bronchain, Patrick Raynal, Henri Chabrol. Does sex influence the network structure of psychopathy?. Personality Disorders: Theory, Research, and Treatment, 2020, 12 (5), pp.421-427. 10.1037/per0000462 . hal-03197032

\section{HAL Id: hal-03197032 \\ https://hal.science/hal-03197032}

Submitted on 13 Apr 2021

HAL is a multi-disciplinary open access archive for the deposit and dissemination of scientific research documents, whether they are published or not. The documents may come from teaching and research institutions in France or abroad, or from public or private research centers.
L'archive ouverte pluridisciplinaire HAL, est destinée au dépôt et à la diffusion de documents scientifiques de niveau recherche, publiés ou non, émanant des établissements d'enseignement et de recherche français ou étrangers, des laboratoires publics ou privés. 
Does sex influence the network structure of psychopathy?

Jonathan Bronchain, Patrick Raynal, \& Henri Chabrol

Centre d'Etudes et de Recherches en Psychopathologie et Psychologie de la Santé, Université de Toulouse, France

\section{Author Note}

Correspondence concerning this article should be addressed to: Jonathan Bronchain,

UFR de Psychologie, Université de Toulouse-Jean Jaurès, 5 allées Antonio Machado, 31058

Toulouse cedex 9. E-mail address: jonathan.bronchain@etu.univ-tlse2.fr. Tel: +33781533109. 


\begin{abstract}
Sex-specific manifestations of psychopathy remain highly debated both at the dimensional and structural levels. The network theory provides a promising framework for investigating this question. Thus, our study aimed to explore the network structure of psychopathy across sex. Participants were 1990 college students (males: 43\%, females: 57\%) who received the Elemental Psychopathy Assessment-Short Form (EPA-SF). We first estimated a Gaussian Graphical Model including the eighteen EPA-SF facets, separately for males and females. We then computed centrality indices (i.e., strength and expected influence), predictability, and finally conducted a bootstrapping procedure to assess the accuracy of edge weights and the stability of the centrality indices. The results of the network comparison test provide support for the stability of the network structure of psychopathic traits across sex. Self-Centeredness was the most central trait in the two networks, followed by Unconcern, Rashness, and Anger for females, and by Callousness, Unconcern, and Rashness for males. Minor sex-differences and future directions are discussed.
\end{abstract}

Keywords: psychopathy; psychopathic traits; gender; sex; network analysis 
Does sex influence the network structure of psychopathy?

The clinical presentation of psychopathy in males and females is the subject of extensive debates (Cale \& Lilienfeld, 2002; Wynn et al., 2012). Psychopathy refers to a personality configuration that encompasses callousness, egocentricity, poor impulse control, and, in some models, boldness/fearless dominance (Cooke \& Michie, 2001; Patrick et al., 2009). Behavioral outcomes of high psychopathic traits have been presented as heterogeneous and dependent on internal (e.g., traits configuration), external (e.g., comorbidities), and contextual factors (Lilienfeld et al., 2015a; Lilienfeld et al., 2015b; Steinert et al., 2017). Among these factors, sex represents a major determinant, still requiring investigation (for an updated review, see Verona \& Vitale, 2018).

Issues regarding sex-specific manifestation of psychopathy can be approached in two ways: (1) prevalence rates and mean levels of psychopathy, and (2) differences in the construct structure. Concerning mean levels, studies in incarcerated populations using the Psychopathy Checklist-Revised (PCL-R; Hare, 1991, 2003) have consistently reported higher scores and higher rates of psychopathy for males compared to females (Jackson et al., 2002; Salekin et al., 1997; Strand \& Belfrage, 2005; Vitale et al., 2002). Females generally display fewer and later-onset antisocial behavior and, therefore, lower scores on antisocial lifestyle items, leading to decreased global psychopathy scores. In community and undergraduate samples, studies have replicated these results with multidimensional models and self-reported data. At the factor-level, males exhibit higher scores on affective, behavioral, and interpersonal components (Anestis et al., 2011; Colins et al., 2016; Miller et al., 2011; Uzieblo et al., 2009). However, and despite these differences in mean levels, studies that used a broader definition of antisociality (e.g., rule-breaking, social aggression) depicted a more complex picture, with females high on psychopathy relying on indirect, verbal, manipulative, or sexual tactics to attain their goals, whereas males tended to more frequently use physical 
violence and intimidation (Forouzan \& Cooke, 2005; Kreis \& Cooke, 2011; Nicholls \& Petrila, 2005). In this line, external correlates of psychopathic traits suggest that affectiveinterpersonal features are stronger predictors of violence for females than antisocial lifestyle features, whereas the opposite is true for males (Richards et al., 2003; Salekin et al., 1998).

Additionally, the study of sex-specific manifestations of psychopathy implies to investigate structural differences and construct non-equivalence across sex. Research in this field indicates comparable interrater (for PCL-R) and internal consistency (for PCL-R and related self-reports) reliabilities of psychopathy measures between males and females (Miller et al., 2014; Sellbom et al., 2015; Vitale et al., 2002; Warren et al., 2003). Studies also regularly reported sex factorial invariance of the main instruments dedicated to assess psychopathic traits (e.g., Anestis et al., 2011; Drislane \& Patrick, 2016; Warren et al., 2003). Regarding differences in item functioning, specific analyses have found that males more readily endorsed, and were better discriminated by criteria assessing affective components of psychopathy (Bolt et al., 2004; Eichenbaum, 2019; Gummelt et al., 2012). More specifically, affective items seem to outperform interpersonal items for discriminating psychopathy in males, while interpersonal items would outperform affective items in females (Schrum \& Salekin, 2006).

Thus, despite convergent evidences supporting the relative construct's equivalence of psychopathy across sex, this question remains debated and needs further investigation. New statistical and conceptual approaches could be useful to supplement the data currently available. In this context, network analyses could be very promising (Borsboom \& Cramer, 2013). While structural models of psychopathology usually describe symptoms as passive indicators of an underlying disease, in the network perspective constructs are conceptualized based on direct and causal relationships between measured dimensions. Network models graphically describe conditional associations between variables after controlling for all other 
variables in the network and allow to discriminate the most central dimensions in the structure. Network analyses have been used to study psychopathy in both incarcerated (Preszler et al., 2018; Verschuere et al., 2018) and community mixed-gender samples (Bronchain et al., 2019; Tsang \& Salekin, 2019). To our knowledge, there is no study reporting a network analysis of psychopathic traits across sex. So, this study aimed to investigate the network structure of psychopathy in males and females and to identify the more central traits in both networks. We expected to replicate the network structure observed in a previous study using the same measure (Bronchain et al., 2019). Regarding specific sex differences, this study should be considered as exploratory.

\section{Method}

\section{Participants and procedures}

Participants were college students from different French universities. Data were collected through an online survey available via social networks. The link was shared on groups specifically dedicated to students. The median completion time was $16.12 \mathrm{~min}$. Twenty-eight participants were excluded for not meeting inclusion criteria (i.e., being a college student over 18 and under 28), and for finishing the study in a time deemed invalid (less than two seconds per item). The final sample $(N=1990)$ consisted of 856 males $(43 \%)$ and 1134 females $(57 \%)$ ranged from 18 to 28 years old; mean age of males $=21.76(S D=$ $2.41)$, mean age of females $=21.20(S D=2.32)$. The study was presented as a survey on personality and behaviors, and no compensation was offered for participation. The participants were assured of the anonymity of their answers and have given their informed consent for participation in the study. This study was approved by the research ethics committee of our institution.

\section{Measures}


Psychopathic personality traits were assessed using the Elemental Psychopathy Assessment-Short Form (EPA-SF; Lynam et al., 2013). The EPA-SF is a 72-item scale, scored from 1 = "Strongly disagree" to 5 = "Strongly agree", that assesses eighteen psychopathy facets (e.g., callousness: "The suffering of others is not my problem"). Lynam et al. (2013) have identified and replicated a four factors structure: Antagonism (A; Callousness, Coldness, Distrust, Manipulation, and Self-Centeredness), Emotional Stability (ES; Invulnerability, Self-Contentment, and Unconcern), Disinhibition (D; Disobliged, Opposition, Rashness, Impersistence, Thrill-Seeking, and Urgency) and Narcissism (N; Anger, Arrogance, Dominance, and Self-Assurance).

\section{Statistical analysis}

Data analysis was conducted in R Version 3.4.0. Prior to the analysis, we imputed missing values (less than 1\%) with the missMDA package (Josse \& Husson, 2016). Skewed distributions of the eighteen EPA-SF facets scores were normalized with a nonparanormal transformation (Liu et al., 2009).

We then used the qgraph package (Epskamp et al., 2012) to estimate two Gaussian Graphical Models (GGM) including the eighteen EPA-SF facets, for both males and females. Spurious edges were removed by relying on the Graphical Least Absolute Shrinkage and Selection Operator (Friedman et al., 2014) with extended Bayesian Information Criterion Model Selection $(\gamma=0.5)$. We used the $m g m$ package (Haslbeck \& Waldrop, 2019) to estimate node predictability. Predictability, visually represented by a ring around a node, quantifies the proportion of variance explained by the other connecting nodes (akin to $R^{2}$ ). Strength and expected influence were computed as centrality indices to investigate the network structure. Strength refers to how well a node is directly connected to other nodes. From a clinical standpoint, a node high in strength is expected to activate many other nodes and represent a potential target for treatment (Fried et al., 2017). However, since simulations 
have indicated that expected influence centrality can outperform strength when networks contain negative edges (Robinaugh et al., 2016) we only used expected influence to relate the centrality of facets in the network. Nonetheless, we reported strength to make our network comparable to previous studies that have used this metric.

Using the bootnet package (Epskamp et al., 2018), we conducted a bootstrapping procedure to assess the accuracy of edge weights and the stability of strength and expected influence metrics. It is recommended to use a correlation stability coefficient (CS-coefficient) to quantify the stability of centrality indices. $C S$-coefficient should not be below 0.25 , and preferably above 0.5 to allow the interpretation of centrality differences. Finally, we conducted a network comparison test, with the NetworkComparisonTest package (van Borkulo et al., 2017), to examine differences for the overall network structure.

The final GGM obtained (Figure 1) was plotted with the qgraph package. In a psychological network, a "node" represents a dimension measured, and an "edge" represents the partial correlation between two dimensions after controlling for all other dimensions. Blue edges represent positive relations among variables and red edges depict negative relations. Thicker and more saturated edges represent stronger associations. The filled part of the ring around each node depicts predictability.

\section{Results}

\section{Descriptive statistics}

Descriptive statistics are presented in Table 1. Males scored higher than females on all EPA-SF factors, except for Distrust, Urgency, Rashness, and Anger.

\section{Network analysis}

Figure 1 shows the correlational structure of psychopathic facets in males and females. The results of stability and accuracy analysis indicated that our network was accurately estimated. Confidence intervals around edge weights were very small and the CS-coefficients 
were all above 0.50 , allowing to interpret differences in centrality for both males and females. Self-Centeredness was the most central trait in the two networks, followed by Unconcern, Rashness, and Anger for females, and by Callousness, Unconcern, and Rashness for males (Figure 2). The network comparison test showed that there were no statistically significant differences for the overall network structure for the two networks $(M=0.10, p=.42)$. We reported the network structure for the total sample (Figure 3) to make our results comparable to previous network analyses based on mixed-gender samples.

The two estimated networks were characterized by similar edges. At the factor level, Unconcern was strongly connected to both Invulnerability and Self-Contentment facets (ES). Dominance and Self-Assurance were the two $\mathrm{N}$ facets sharing the most important edge. SelfCenteredness and Callousness were strongly linked, as central A dimensions, and Rashness was closely related to the other D facets, except Impersistence.

Regarding inter-facets correlations, A, ES, D, and N displayed important mutual edges. Urgency (D) was negatively linked to both Self-contentment and Invulnerability (ES), and strongly positively link to Anger (N). Distrust (A) shared negative edges with SelfAssurance (N) and Self-Contentment (ES). Self-Contentment (ES) displayed the same structural configuration across sex and was positively linked to Unconcern (ES), SelfAssurance and Dominance (N), Self-Centeredness (A), and negatively linked to Urgency (D) and Distrust (A). Finally, it is worth noting that the only facet showing no edge with the others was Impersistence (D).

Despite these similarities, we could observe some structural differences between the male and female networks. For females, Manipulation (A) shared positive edges with Disobliged, Opposition (D), Self-Centeredness (A), Arrogance, Dominance (N), and Invulnerability (ES), while for males Arrogance and Invulnerability were not connected, and Thrill-Seeking (D) was positively linked to Manipulation. In this line, Callousness displayed 
positive edges with Coldness, Distrust, and Self-Centeredness (A) in the two networks, but was positively linked to Arrogance (N) only in the male network, while it was positively linked to Anger (N) and negatively link to Self-Assurance $(\mathrm{N})$ only in the female network.

\section{Discussion}

This study aimed to investigate the network structure of psychopathic traits across sex in an undergraduate sample. We first estimated a GGM including the eighteen dimensions of the EPA-SF. We then computed centrality indices (i.e., strength and expected influence) and predictability, and we finally conducted a bootstrapping procedure to assess the accuracy of edge weights and the stability of the centrality indices. The final model depicted strong interfactor edges for ES, D, N, and A with a comparable correlational structure for males and females. The network comparison test also suggested a similar overall network structure. Selfcenteredness (e.g., "I'm not all that concerned with other peoples' needs") was the most central trait for the two networks, followed by Unconcern and Rashness. This result is consistent with both classical description of psychopathy (Cooke \& Michie, 2001; Hare, 1996) and previous network analyses (Tsang \& Salekin, 2019) that identified egocentricityrelated traits, as central to the psychopathy construct. Moreover, in line with recent reports (e.g., Lynam \& Miller, 2019), Antagonism appeared to be very central in the psychopathy construct, with Self-Centeredness and Callousness among the three nodes with the highest level of expected influence.

Minor sex differences were observed in Callousness, more central in males, and Anger more central in females. These differences may illustrate clinical observations and empirical data reporting more emotional instability in female psychopathy (Kreis \& Cooke, 2011; Sprague et al., 2012). Additionally, it is worth noting that, depending on sex, certain facets did not have exactly the same neighborhood nodes. For instance, Manipulation was related to a common root of Dominance, Self-Centeredness, Disobliged, and Opposition in the two 
networks, but was connected to Thrill-Seeking only for males, and to Invulnerability and Arrogance only for females. This may express a different function of manipulative tendencies by sex, with females more driven by the grandiose/vulnerable narcissism aspect of psychopathy, while males could find there a way of facing danger and risk.

Conversely, other facets, such as Unconcern (e.g., "It takes a lot to make me nervous or anxious") displayed both a high centrality and a similar pattern of correlations in males and females. Unconcern, as well as Self-Contentment and Invulnerability, operationalized in part boldness-related traits (i.e., stress immunity, social potency, self-assurance, social efficacy) in the EPA-SF. Without concluding the relevance of boldness-related traits in the psychopathy construct (core trait vs. diagnostic specifier; see Lilienfeld et al., 2012; Lynam \& Miller, 2012), our results suggest that these traits have the same structure in males and females and displayed consistent positive and negative associations with other, more established, psychopathic traits. Despite their divergence, our data complement the previous study that indicated no meaningful incremental validity of boldness for predicting PCL-R scores in female incarcerated samples (Murphy et al., 2016), and could express a specific centrality of boldness in non-incarcerated samples.

Several limitations should be considered in the present study. First, the current study used data collected from an online sample recruited via social networks. Although there is growing evidence that Internet data collection methods are consistent with more traditional sampling approaches (Ramsey et al., 2016; Walter et al., 2019), some caution must be used, as in all studies, regarding the generalizability of the results. Second, some authors argued that network characteristics vary substantially across samples, displayed poor replicability, limited generalizability, and therefore no substantial utility (Forbes et al., 2017b, 2017a). However, each of these points has been addressed and recent research reports evidence that psychopathological network replicates very well across samples (Borsboom et al., 2017; 
Steinley et al., 2017). Additionally, we could note that the two networks generated in this study widely replicate findings from Bronchain et al. (2019). Third and finally, given this study was based on biological sex, future research would benefit from investigating the complex relationship between gender and psychopathy.

In conclusion, despite these limitations our study has several strengths, including a large sample of participants and the first use of the network theory to investigate the sexspecific manifestation of psychopathy. Our results brought information regarding the stability of the network structure of psychopathy across sex. The network structure of psychopathic traits in undergraduate does not seem to be influenced by sex and the minor underlined differences do not allow to claim the non-equivalence of the construct in males and females. However, there is a need to replicate these findings, and future studies should explore the stability of the network structure in high psychopathic traits individuals. 


\section{References}

Anestis, J. C., Caron, K. M., \& Carbonell, J. L. (2011). Examining the Impact of Gender on the Factor Structure of the Psychopathic Personality Inventory-Revised. Assessment, 18(3), 340-349. https://doi.org/10.1177/1073191111403243

Bolt, D. M., Hare, R. D., Vitale, J. E., \& Newman, J. P. (2004). A multigroup item response theory analysis of the psychopathy checklist—Revised. Psychological Assessment, 16(2), 155-168. https://doi.org/10.1037/1040-3590.16.2.155

Borsboom, D., \& Cramer, A. O. J. (2013). Network Analysis: An Integrative Approach to the Structure of Psychopathology. Annual Review of Clinical Psychology, 9(1), 91-121. https://doi.org/10.1146/annurev-clinpsy-050212-185608

Borsboom, D., Fried, E. I., Epskamp, S., Waldorp, L. J., van Borkulo, C. D., van der Maas, H. L. J., \& Cramer, A. O. J. (2017). False alarm? A comprehensive reanalysis of "Evidence that psychopathology symptom networks have limited replicability" by Forbes, Wright, Markon, and Krueger (2017). Journal of Abnormal Psychology, 126(7), 989-999. PubMed. https://doi.org/10.1037/abn0000306

Bronchain, J., Raynal, P., \& Chabrol, H. (2019). The network structure of psychopathic personality traits in a non-institutionalized sample. Personality and Individual Differences, 146, 41-45. https://doi.org/10.1016/j.paid.2019.03.044

Cale, E. M., \& Lilienfeld, S. O. (2002). Sex differences in psychopathy and antisocial personality disorder: A review and integration. Clinical Psychology Review, 22(8), 1179-1207. https://doi.org/10.1016/S0272-7358(01)00125-8

Colins, O. F., Fanti, K. A., Salekin, R. T., \& Andershed, H. (2016). Psychopathic Personality in the General Population: Differences and Similarities Across Gender. Journal of Personality Disorders, 31(1), 49-74. https://doi.org/10.1521/pedi_2016_30_237 
Cooke, D., \& Michie, C. (2001). Refining the construct of psychopathy: Towards a hierarchical model. Psychological Assessment, 13(2), 171-188. https://doi.org/10.1037//1040-3590.13.2.171

Drislane, L. E., \& Patrick, C. J. (2016). Integrating Alternative Conceptions of Psychopathic Personality: A Latent Variable Model of Triarchic Psychopathy Constructs. Journal of Personality Disorders, 31(1), 110-132. https://doi.org/10.1521/pedi_2016_30_240

Eichenbaum, A. (2019). Item Response Theory Analysis of the TriPM [Unpublished thesis, Washington State University]. https://research.libraries.wsu.edu:8443/xmlui/bitstream/handle/2376/16791/Eichenbau m_wsu_0251E_12605.pdf?sequence=1

Epskamp, S., Borsboom, D., \& Fried, E. I. (2018). Estimating psychological networks and their accuracy: A tutorial paper. Behavior Research Methods, 50(1), 195-212. https://doi.org/10.3758/s13428-017-0862-1

Epskamp, S., Cramer, A., Waldorp, L., Schmittmann, V., \& Borsboom, D. (2012). qgraph: Network Visualizations of Relationships in Psychometric Data. Journal of Statistical Software, 48(4), 1-18. https://doi.org/10.18637/jss.v048.i04

Forbes, M. K., Wright, A. G. C., Markon, K. E., \& Krueger, R. F. (2017a). Evidence that psychopathology symptom networks have limited replicability. Journal of Abnormal Psychology, 126(7), 969-988. https://doi.org/10.1037/abn0000276

Forbes, M. K., Wright, A. G. C., Markon, K. E., \& Krueger, R. F. (2017b). Further evidence that psychopathology networks have limited replicability and utility: Response to Borsboom et al. (2017) and Steinley et al. (2017). Journal of Abnormal Psychology, 126(7), 1011-1016. https://doi.org/10.1037/abn0000313 
Forouzan, E., \& Cooke, D. J. (2005). Figuring out la femme fatale: Conceptual and assessment issues concerning psychopathy in females. Behavioral Sciences \& the Law, 23(6), 765-778. https://doi.org/10.1002/bsl.669

Fried, E. I., van Borkulo, C. D., Cramer, A. O. J., Boschloo, L., Schoevers, R. A., \& Borsboom, D. (2017). Mental disorders as networks of problems: A review of recent insights. Social Psychiatry and Psychiatric Epidemiology, 52(1), 1-10. https://doi.org/10.1007/s00127-016-1319-z

Friedman, J. H., Hastie, T., \& Tibshirani, R. (2014). Glasso: Graphical lasso-Estimation of Gaussian graphical models. R package version 1.8.

Gummelt, H. D., Anestis, J. C., \& Carbonell, J. L. (2012). Examining the Levenson Self Report Psychopathy Scale using a Graded Response Model. Personality and Individual Differences, 53(8), 1002-1006. https://doi.org/10.1016/j.paid.2012.07.014

Hare, R. D. (1991). The Hare psychopathy checklist-revised: Manual. Multi-Health Systems. Hare, R. D. (1996). Psychopathy: A Clinical Construct Whose Time Has Come. Criminal Justice and Behavior, 23(1), 25-54. https://doi.org/10.1177/0093854896023001004

Hare, R. D. (2003). Manual for the Hare Psychopathy Checklist-Revised (PCL-R) 2nd edition. Multi-Health Systems.

Haslbeck, J., \& Waldrop, L. J. (2019). MGM: Estimating Time-Varying Mixed Graphical Models in High-Dimensional Data. Arxiv Preprint.

Jackson, R. L., Rogers, R., Neumann, C. S., \& Lambert, P. L. (2002). Psychopathy in Female Offenders: An Investigation of Its Underlying Dimensions. Criminal Justice and Behavior, 29(6), 692-704. https://doi.org/10.1177/009385402237922

Josse, J., \& Husson, F. (2016). MissMDA: A Package for Handling Missing Values in Multivariate Data Analysis. Journal of Statistical Software, 70(1), 1-31. https://doi.org/doi: 10.18637/jss.v070.i01 
Kreis, M. K. F., \& Cooke, D. J. (2011). Capturing the Psychopathic Female: A Prototypicality Analysis of the Comprehensive Assessment of Psychopathic Personality (CAPP) Across Gender. Behavioral Sciences \& the Law, 29(5), 634-648. https://doi.org/10.1002/bsl.1003

Lilienfeld, S. O., Patrick, C. J., Benning, S. D., Berg, J., Sellbom, M., \& Edens, J. F. (2012). The role of fearless dominance in psychopathy: Confusions, controversies, and clarifications. Personality Disorders, 3(3), 327-340. https://doi.org/10.1037/a0026987

Lilienfeld, S. O., Watts, A. L., Francis Smith, S., Berg, J. M., \& Latzman, R. D. (2015). Psychopathy Deconstructed and Reconstructed: Identifying and Assembling the Personality Building Blocks of Cleckley’s Chimera. Journal of Personality, 83(6), 593-610. https://doi.org/10.1111/jopy.12118

Lilienfeld, S. O., Watts, A. L., \& Smith, S. F. (2015). Successful Psychopathy: A Scientific Status Report. Current Directions in Psychological Science, 24(4), 298-303. https://doi.org/10.1177/0963721415580297

Liu, H., Lafferty, J., \& Wasserman, L. (2009). The nonparanormal: Semiparametric estimation of high dimensional undirected graphs. Journal of Machine Learning Research, 10, 2295-2328.

Lynam, D. R., \& Miller, J. D. (2012). Fearless dominance and psychopathy: A response to Lilienfeld et al. Personality Disorders, 3(3), 341-353. https://doi.org/10.1037/a0028296

Lynam, D. R., \& Miller, J. D. (2019). The basic trait of Antagonism: An unfortunately underappreciated construct. Journal of Research in Personality, 81, 118-126. https://doi.org/10.1016/j.jrp.2019.05.012 
Lynam, D. R., Sherman, E. D., Samuel, D., Miller, J. D., Few, L. R., \& Widiger, T. A. (2013). Development of a Short Form of the Elemental Psychopathy Assessment. Assessment, 20(6), 659-669. https://doi.org/10.1177/1073191113502072

Miller, J. D., Hyatt, C. S., Rausher, S., Maples, J. L., \& Zeichner, A. (2014). A test of the construct validity of the elemental psychopathy assessment scores in a community sample of adults. Psychological Assessment, 26(2), 555-562. https://doi.org/10.1037/a0035952

Miller, J. D., Watts, A., \& Jones, S. E. (2011). Does psychopathy manifest divergent relations with components of its nomological network depending on gender? Personality and Individual Differences, 50(5), 564-569. https://doi.org/10.1016/j.paid.2010.11.028

Murphy, B., Lilienfeld, S., Skeem, J., \& Edens, J. F. (2016). Are fearless dominance traits superfluous in operationalizing psychopathy? Incremental validity and sex differences. Psychological Assessment, 28(12), 1597-1607. https://doi.org/10.1037/pas0000288

Nicholls, T. L., \& Petrila, J. (2005). Gender and psychopathy: An overview of important issues and introduction to the special issue. Behavioral Sciences \& the Law, 23(6), 729-741. https://doi.org/10.1002/bs1.677

Patrick, C. J., Fowles, D. C., \& Krueger, R. F. (2009). Triarchic conceptualization of psychopathy: Developmental origins of disinhibition, boldness, and meanness. Development and Psychopathology, 21(3), 913-938. https://doi.org/10.1017/S0954579409000492

Preszler, J., Marcus, D. K., Edens, J. F., \& McDermott, B. E. (2018). Network analysis of psychopathy in forensic patients. Journal of Abnormal Psychology, 127(2), 171-182. https://doi.org/10.1037/abn0000325 
Ramsey, S. R., Thompson, K. L., McKenzie, M., \& Rosenbaum, A. (2016). Psychological research in the internet age: The quality of web-based data. Computers in Human Behavior, 58, 354-360. https://doi.org/10.1016/j.chb.2015.12.049

Richards, H. J., Casey, J. O., \& Lucente, S. W. (2003). Psychopathy And Treatment Response In Incarcerated Female Substance Abusers. Criminal Justice and Behavior, 30(2), 251-276. https://doi.org/10.1177/0093854802251010

Robinaugh, D. J., Millner, A. J., \& McNally, R. J. (2016). Identifying highly influential nodes in the complicated grief network. Journal of Abnormal Psychology, 125(6), 747-757. https://doi.org/10.1037/abn0000181

Salekin, R., Rogers, R., \& Sewell, K. (1997). Construct validity of psychopathy in a female offender sample: A multitrait-multimethod evaluation. Journal of Abnormal Psychology, 106(4), 576-585. https://doi.org/10.1037//0021-843x.106.4.576

Salekin, R. T., Rogers, R., Ustad, K. L., \& Sewell, K. W. (1998). Psychopathy and Recidivism Among Female Inmates. Law and Human Behavior, 22(1), 109-128. https://doi.org/10.1023/A:1025780806538

Schrum, C. L., \& Salekin, R. T. (2006). Psychopathy in adolescent female offenders: An item response theory analysis of the psychopathy checklist: Youth version. Behavioral Sciences \& the Law, 24(1), 39-63. https://doi.org/10.1002/bsl.679

Sellbom, M., Drislane, L. E., Johnson, A. K., Goodwin, B. E., Phillips, T. R., \& Patrick, C. J. (2015). Development and Validation of MMPI-2-RF Scales for Indexing Triarchic Psychopathy Constructs. Assessment, 23(5), 527-543. https://doi.org/10.1177/1073191115590853

Sprague, J., Javdani, S., Sadeh, N., Newman, J. P., \& Verona, E. (2012). Borderline personality disorder as a female phenotypic expression of psychopathy? Personality Disorders, 3(2), 127-139. https://doi.org/10.1037/a0024134 
Steinert, S. W., Lishner, D. A., Vitacco, M. J., \& Hong, P. Y. (2017). Conceptualizing successful psychopathy: An elaboration of the moderated-expression model. Aggression and Violent Behavior, 36, 44-51. https://doi.org/10.1016/j.avb.2017.07.005

Steinley, D., Hoffman, M., Brusco, M. J., \& Sher, K. J. (2017). A method for making inferences in network analysis: Comment on Forbes, Wright, Markon, and Krueger (2017). Journal of Abnormal Psychology, 126(7), 1000-1010. https://doi.org/10.1037/abn0000308

Strand, S., \& Belfrage, H. (2005). Gender differences in psychopathy in a swedish offender sample. Behavioral Sciences \& the Law, 23(6), 837-850. https://doi.org/10.1002/bsl.674

Tsang, S., \& Salekin, R. T. (2019). The network of psychopathic personality traits: A network analysis of four self-report measures of psychopathy. Personality Disorders, 10(3), 246-256. https://doi.org/10.1037/per0000319

Uzieblo, K., Verschuere, B., Van den Bussche, E., \& Crombez, G. (2009). The Validity of the Psychopathic Personality Inventory—Revised in a Community Sample. Assessment, 17(3), 334-346. https://doi.org/10.1177/1073191109356544

van Borkulo, C. D., Boschloo, L., Kossakowski, J. J., Tio, P., Schoevers, R. A., Borsboom, D., \& Boschloo, L. (2017). Comparing network structures on three aspects: A permutation test. Unpublished Manuscript. https://doi.org/10.13140/RG.2.2.29455.38569

Verona, E., \& Vitale, J. (2018). Psychopathy in women: Assessment, manifestations, and etiology. In Handbook of psychopathy (C. J. Patrick, pp. 509-528). Guilford Press. Verschuere, B., van Ghesel Grothe, S., Waldorp, L., Watts, A. L., Lilienfeld, S. O., Edens, J. F., Skeem, J. L., \& Noordhof, A. (2018). What features of psychopathy might be 
central? A network analysis of the Psychopathy Checklist-Revised (PCL-R) in three large samples. Journal of Abnormal Psychology, 127(1), 51-65. https://doi.org/10.1037/abn0000315

Vitale, J. E., Smith, S. S., Brinkley, C. A., \& Newman, J. P. (2002). The Reliability and Validity of the Psychopathy Checklist-Revised in a Sample of Female Offenders. Criminal Justice and Behavior, 29(2), 202-231. https://doi.org/10.1177/0093854802029002005

Walter, S. L., Seibert, S. E., Goering, D., \& O’Boyle, E. H. (2019). A Tale of Two Sample Sources: Do Results from Online Panel Data and Conventional Data Converge? Journal of Business and Psychology, 34(4), 425-452. https://doi.org/10.1007/s10869018-9552-y

Warren, J. I., Burnette, M. L., South, S. C., Chauhan, P., Bale, R., Friend, R., \& Van Patten, I. (2003). Psychopathy in women: Structural modeling and comorbidity. International Journal of Law and Psychiatry, 26(3), 223-242. https://doi.org/10.1016/s01602527(03)00034-7

Wynn, R., Høiseth, M. H., \& Pettersen, G. (2012). Psychopathy in women: Theoretical and clinical perspectives. International Journal of Women's Health, 4, 257-263. https://doi.org/10.2147/IJWH.S25518 
Table 1. Descriptive statistics, $t$-test, and Cohen's $d$ for the EPA-SF dimensions.

\begin{tabular}{|c|c|c|c|c|c|c|c|}
\hline Variable & Range & Skewness & Kurtosis & $\begin{array}{l}\text { Males } \\
M(S D)\end{array}$ & $\begin{array}{c}\text { Females } \\
M(S D)\end{array}$ & $t$ & $d$ \\
\hline Global psychopathy & $119-284$ & 0.42 & 0.34 & $188.92(23.67)$ & $175.99(22.91)$ & $12.28 *$ & .56 \\
\hline Antagonism & 24-92 & 0.82 & 1.10 & $47.86(10.28)$ & $43.29(9.24)$ & $10.40 *$ & .47 \\
\hline Coldness & $4-20$ & 1.14 & 1.63 & $7.99(2.65)$ & $7.32(2.47)$ & $5.84 *$ & .26 \\
\hline Distrust & $4-20$ & -0.01 & -0.33 & $12.16(2.97)$ & $12.43(2.88)$ & -2.06 & .09 \\
\hline Manipulation & $4-20$ & 0.55 & -0.18 & $10.79(3.53)$ & $8.97(3.09)$ & $12.25^{*}$ & .54 \\
\hline Self-Centeredness & $4-20$ & 0.91 & 0.99 & $9.03(2.99)$ & $7.66(2.58)$ & $10.91 *$ & .49 \\
\hline Callousness & $4-20$ & 1.15 & 1.63 & $7.90(2.80)$ & $6.92(2.46)$ & $8.31 *$ & .37 \\
\hline Disinhibition & $30-96$ & 0.28 & -0.07 & $60.65(10.68)$ & 59.28 (11.05) & $3.77 *$ & .12 \\
\hline Urgency & $4-20$ & -0.01 & -0.73 & $11.29(3.57)$ & $12.83(3.54)$ & $-9.55^{*}$ & .43 \\
\hline Thrill-Seeking & $4-20$ & 0.43 & -0.61 & $10.45(4.01)$ & $9.24(3.69)$ & $6.99 *$ & .31 \\
\hline Opposition & $4-20$ & 0.24 & -0.57 & $10.98(3.50)$ & $10.20(3.35)$ & $5.03 *$ & .22 \\
\hline Disobliged & $4-17$ & 0.79 & 1.10 & $7.13(2.02)$ & $6.58(1.90)$ & $6.24 *$ & .28 \\
\hline Impersistence & $5-19$ & 0.19 & 0.09 & $11.25(2.04)$ & $10.81(1.83)$ & $5.09 *$ & .22 \\
\hline Rashness & $4-20$ & 0.55 & -0.22 & $9.54(3.37)$ & $9.61(3.56)$ & -0.49 & .02 \\
\hline Narcissism & $16-76$ & 0.23 & -0.04 & $43.11(9.04)$ & $42.68(8.28)$ & 1.16 & .06 \\
\hline Anger & $4-20$ & 0.23 & -0.77 & $9.81(3.46)$ & $11.49(3.75)$ & $-10.23 *$ & .46 \\
\hline Self-Assurance & $4-20$ & 0.14 & -0.79 & $11.53(3.62)$ & $10.41(3.69)$ & $6.74 *$ & .31 \\
\hline Dominance & $4-20$ & 0.01 & -0.46 & $12.01(3.25)$ & $11.87(3.26)$ & 0.96 & .04 \\
\hline Arrogance & $4-19$ & 0.72 & 0.64 & $9.76(2.51)$ & $8.91(2.16)$ & $8.10 *$ & .36 \\
\hline Emotional Stability & $12-60$ & 0.25 & -0.50 & $37.29(8.94)$ & $30.74(8.33)$ & $16.84 *$ & .76 \\
\hline Unconcern & $4-20$ & 0.48 & -0.62 & $11.50(4.08)$ & $8.95(3.65)$ & $14.70 *$ & .66 \\
\hline Self-Contentment & $4-20$ & 0.33 & -0.47 & $11.25(3.54)$ & $9.63(3.29)$ & $10.50 *$ & .47 \\
\hline Invulnerability & $4-20$ & -0.21 & -0.38 & $14.54(3.10)$ & $12.16(3.24)$ & $16.50 *$ & .75 \\
\hline
\end{tabular}

$* p<.01$ 

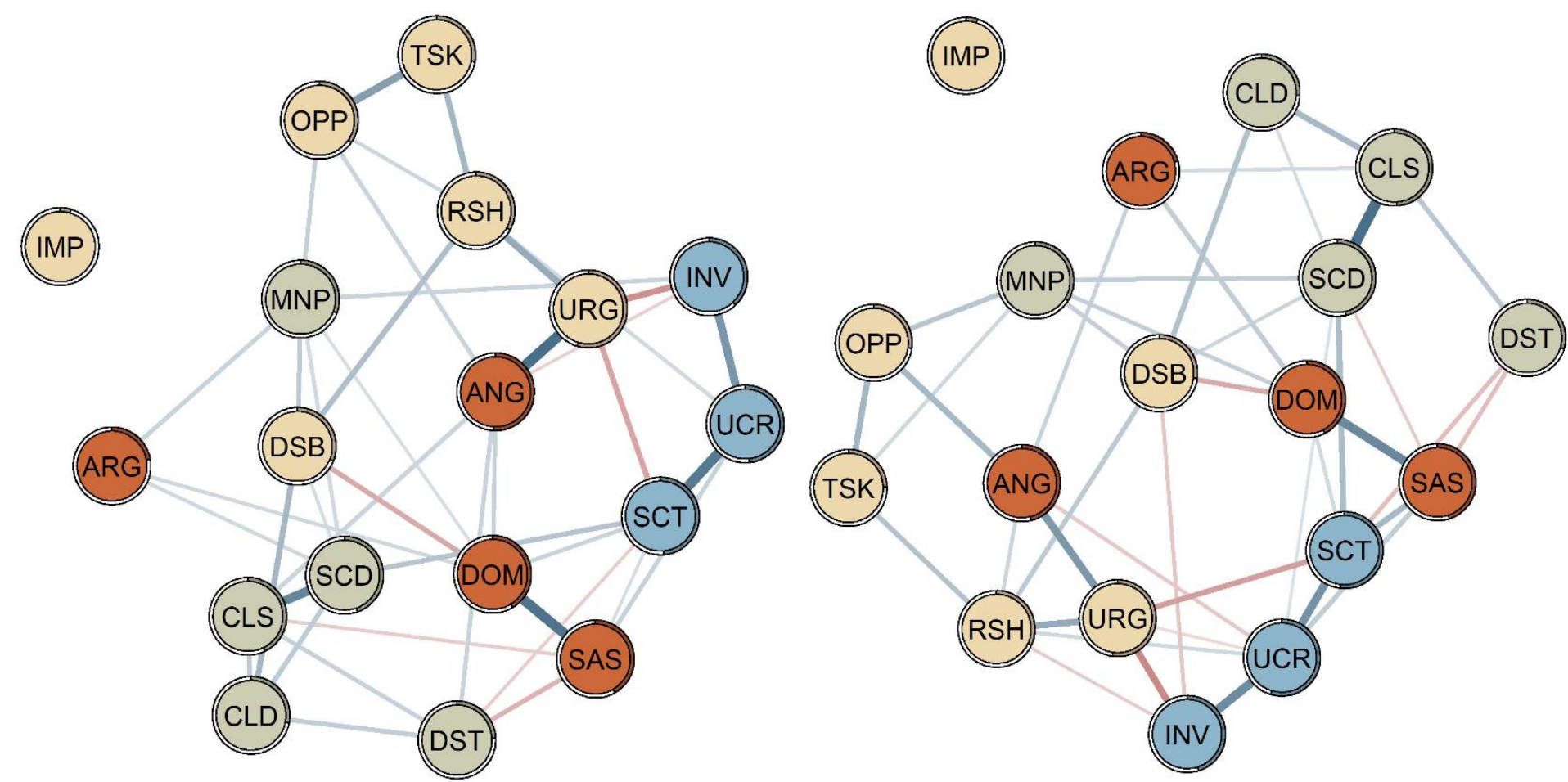

Antagonism

- CLD: Coldness

- DST: Distrust

- MNP: Manipulation

- SCD: Self-Centeredness

- CLS: Callousness

Emotional Stability

- UCR: Unconcern

- SCT: Self-Contentment

- INV: Invulnerability

Disinhibition

- URG: Urgency

- TSK: Thrill-Seeking

- OPP: Opposition

- DSB: Disobliged

- IMP: Impersistence

- RSH: Rashness

Narcissism

- ANG: Anger

- SAS: Self-Assurance

- DOM: Dominance

- ARG: Arrogance

Fig. 1. Network displaying the relationships between the 18 EPA-SF psychopathic traits, for females (left panel) and males (right panel). Blue edges represent positive partial correlations, red edges represent negative partial correlations. Thickness and saturation of edges depict the strength of associations. The filled part of the ring around each node depicts predictability: the variance of the node explained by all its neighbors. 

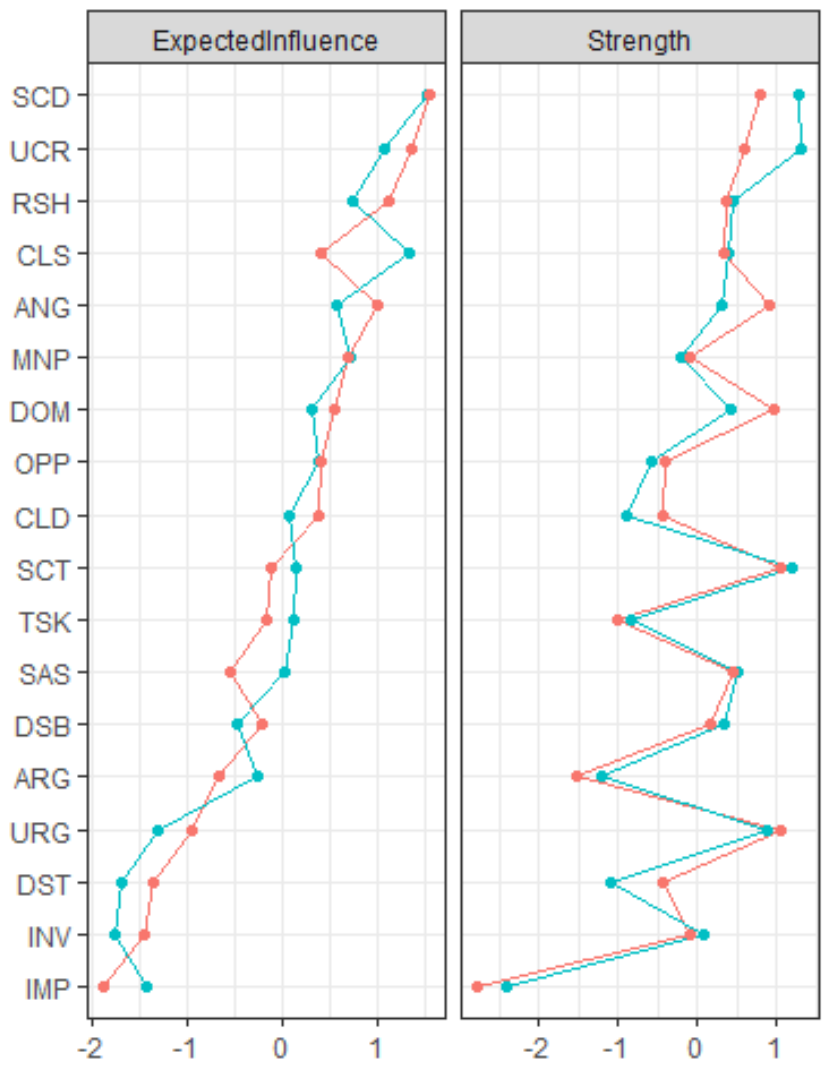

Fig. 2. Centrality plot for the estimated network ordered by Expected Influence. The red line represents females, the blue line represents males. $\mathrm{ANG}=$ anger, $\mathrm{ARG}=$ arrogance, $\mathrm{CLS}=$ callousness, $\mathrm{CLD}=$ coldness, $\mathrm{DSB}=$ disobliged, $\mathrm{DST}=$ distrust, $\mathrm{DOM}=$ dominance, $\mathrm{IMP}=$ impersistence, $\mathrm{INV}=$ invulnerability, $\mathrm{MNP}=$ manipulation, $\mathrm{OPP}=$ opposition, $\mathrm{RSH}=$ rashness, $\mathrm{SAS}=$ self-assurance, $\mathrm{SCD}=$ self-centeredness, $\mathrm{SCT}=$ self-contentment, TSK = thrill-seeking, UCR = unconcern, URG = urgency 


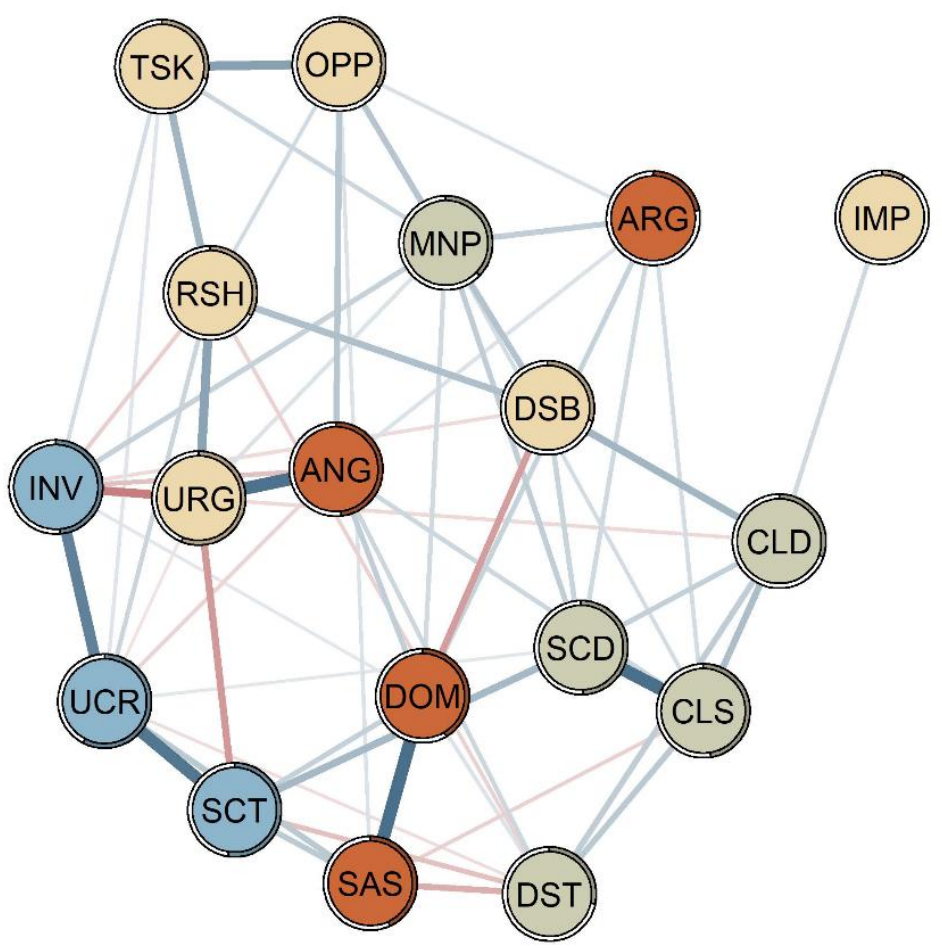

Antagonism

- CLD: Coldness

- DST: Distrust

- MNP: Manipulation

- SCD: Self-Centeredness

- CLS: Callousness

Emotional Stability

- UCR: Unconcern

- SCT: Self-Contentment

- INV: Invulnerability

\section{Disinhibition}

URG: Urgency

- TSK: Thrill-Seeking

O OPP: Opposition

- DSB: Disobliged

- IMP: Impersistence

RSH: Rashness

Narcissism

- ANG: Anger

- SAS: Self-Assurance

- DOM: Dominance

- ARG: Arrogance

Fig. 3. Network displaying the relationships between the 18 EPA-SF psychopathic traits for the total sample $(N=1990)$ 